\title{
De la función económica del cheque, del cheque común al de pago diferido
}

\section{Of the economic function of the check, of the check common to the deferred payment}

DOI: http://dx.doi.org/10.17981/juridcuc.13.1.2017.8

Artículo de investigación. Fecha de recepción: 11/07/2017 Fecha de aceptación: 14/09/2017

\author{
José Luis Zúñiga Ordóñez ${ }^{1}$ \\ Universidad Cooperativa de Colombia. Sede Popayán (Colombia) \\ jose.zunigao@campusucc.edu.co
}

Para citar este artículo:

Zúñiga, J. (2017). De la función económica del cheque, del cheque común al de pago diferido. JURÍDICAS CUC, vol. 13, no. 1, pp. 183-198. DOI: http://dx.doi.org/10.17981/juridcuc.13.1.2017.8

\section{Resumen}

El cheque, desde su adopción en la legislación nacional, ha tenido como función económica ser un medio de pago, sin embargo, los usos mercantiles le han dado a este instrumento una función crediticia, pactándose fechas de pago posteriores a la de su creación o libramiento. Por consiguiente, se analiza su forma de vencimiento y si su modificación lo desnaturalizaría o, por el contrario, le daría mayores alcances en concordancia con las necesidades de la negociación cambiaria.

\footnotetext{
${ }^{1}$ Doctorante en Derecho de la Universidad Sergio Arboleda. Magíster en Derecho de la Universidad Sergio Arboleda. Especialista en Derecho Comercial de la Universidad de San Buenaventura Pontificia Bolivariana. Abogado de la Universidad Cooperativa de Colombia. Docente de tiempo completo en la Universidad Cooperativa de Colombia, Sede Popayán.
}

- The author; licensee Universidad de la Costa - CUC. 
En esa tarea, en un estudio descriptivo y comparativo, se observó que en otras legislaciones sudamericanas, especialmente en Argentina, existe el "cheque de pago diferido" con pleno uso comercial, incluso es alternativa de las pymes para acceder al mercado de valores, concluyendo entonces que el país está en mora de legislar al respecto, lo cual no es una labor difícil dado que compartimos la misma fuente en materia de títulos-valores, esto es el proyecto INTAL, así como una misma familia jurídica.

\section{Palabras clave}

Cheque, cheque de pago diferido, usos mercantiles, redescuento

\section{Abstract}

One of the securities that has a current use in the market is the check, which, because of the technologies in the use of cash in bank current account, in a certain way, leaves it in disuse, however, and as One way to give renewed force to this instrument is to allow it a credit function that in Colombian law does not have, that is to say, that it can validly agree a date later or postdate to the one of the release, however, our country, Would imply a change of approach from the legislative one, since the check in Colombia is a means of payment and the post date is proscribed, as such, deserves to make a study of the figure in comparative law, in order to establish if there are experiences In this regard, the document presents interesting experiences from South American countries that can serve as inspiration for the academy and the legislature, in order to provide a tool to facilitate the Commercial transactions in the country and update the Colombian commercial legislation.

\section{Keywords}

Check, deferred payment check, commercial uses, rediscount 


\section{INTRODUCCIÓN}

Uno de los títulos-valores que tiene un uso corriente en el mercado es el cheque, el cual, a causa de las tecnologías en el uso de efectivo en cuenta corriente bancaria, de cierta forma queda en desuso. No obstante, y como una manera de darle vigencia renovada a este instrumento, es sería ideal permitirle una función crediticia que en la legislación colombiana no tiene, es decir, que se pueda válidamente pactar una fecha posterior o posfecha a la del libramiento. Sin embargo, en nuestro país, implicaría un cambio de enfoque desde lo legislativo, ya que el cheque en Colombia es un medio de pago y la posfecha está proscrita. Como tal, se merece hacer un estudio de la figura en el derecho comparado a fin de establecer si existen experiencias al respecto en ese cometido. Este documento presenta experiencias interesantes de países sudamericanos que pueden servir de inspiración para la academia y el poder legislativo a efecto de otorgar una herramienta que contribuya a facilitar las transacciones comerciales en el país y actualice la legislación comercial colombiana.

\section{METODOLOGÍA}

A partir de la existencia en el escenario económico colombiano de las pymes, con respecto a sus necesidades de financiación y del papel que juegan los operadores financieros en el mantenimiento y crecimiento del sector y de las usanzas en el mercado, concretamente del cheque, se ha desarrollado un estudio descriptivo, analizando y estudiando la regulación legal en nuestro país, pero extendiendo este análisis a manifestaciones legales de otros países que comparten nuestra posición y desarrollo económico.

De igual manera, se hizo un estudio a efecto de determinar las razones fácticas quellevaron a otras legislaciones a incorporar el cheque de pago diferido con esto poder determinar la viabilidad de su adopción en el ordenamiento jurídico colombiano. 
Para ello se toman algunos de los países de mayor relevancia en nuestro hemisferio, como Argentina, Uruguay y Perú, entre otros.

\section{A.El cheque en Colombia: un medio de pago}

En torno a la institución de los títulos-valores, se debe destacar que su función en el ordenamiento jurídico es la de proteger el crédito. No obstante, el cheque como tal tiene una función específica que es la de servir como medio de pago, a pesar de esta realidad legislativa los usos entre los comerciantes desde tiempo atrás, no solo en Colombia, le han dado al cheque una usanza diferente: la de ser instrumento crediticio. Ante esta realidad, el legislador colombiano ha permanecido impávido, como tal, aquella "utilidad" que los comerciantes y personas del común le vienen dando a un cheque, adolece de soporte legal. Este statu quo, para los más radicales intérpretes del derecho, se trata de una situación ilegal que solo podrá cambiar con una reforma legislativa y desde un punto de vista positivista y finalista, sería contradictoria una interpretación diferente, teniendo en cuenta el carácter de orden público de las normas cambiarias. Pero, ¿cuántas transacciones y arreglos se hacen hoy en día con los denominados cheques posfechados proscritos por nuestro estatuto mercantil? Agudelo (2001) al respecto de la interpretación jurídica dice: "La hermenéutica jurídica en la sociedad debe estar en función de la vida, entendiendo lo vital no como algo meramente bilógico, sino como aquella realidad donde se desarrollan potencialidades humanas, donde se puede encontrar lo múltiple." (p. 152 y 153).

El legislador entonces debe adecuar las normas a la realidad, de lo contrario, la misma norma empieza a tener un problema de eficacia, especialmente en el derecho comercial, en el cual, dado su origen consuetudinario y las dinámicas propias del comercio, en muchas ocasiones se realizan comportamientos reiterados y uniformes no regulados por la ley positiva; se trata de una de las características que definen a 
esta especie del derecho privado. Velásquez (1998, p. 94) en consideración a la preponderancia de los usos y costumbres dice: "Casi siempre sucede que los negocios se desarrollan y evolucionan con mayor rapidez que la ley y que, por tanto, cuando ésta llega, por ejemplo, a regular determinadas formas contractuales, tales formas ya existen en la realidad desde tiempo atrás."

Las barreras a un cheque que no sea pagadero a su presentación o a la vista, es decir, que permita un pago posterior a la fecha de su libramiento, están en la misma codificación:

"Artículo 717: El cheque siempre será pagadero a la vista. Cualquier anotación en contrario se tendrá por no puesta. El cheque post datado será pagadero a su presentación." (República de Colombia, 2008).

La mención de que cualquier anotación en el cheque indicativa de una fecha de pago posterior a su creación, incluso al mismo día, será ineficaz de pleno derecho, es decir, el acto jurídico de fijar un plazo dispuesto por el creador en el título mismo no genera efecto jurídico alguno, como tal, quien sea beneficiario o tenedor podrá acudir al banco librado y obtener el pago en caso de provisión de fondos a pesar de la post fecha, arropando de mala fe el acuerdo previo sin posibilidad para el girador de algún reclamo judicial. La inexistencia es la sanción para el cheque post fechado. "En la inexistencia, el negocio no nace a la vida jurídica; no hay negocio; no se estructura, no alcanza a perfeccionarse; no se constituye" (Bohórquez, 1998, p. 91).

El cheque con fecha posterior deberá ser pagado por el banco so pena de verse abocado en situaciones de responsabilidad civil en virtud del artículo 720 del Código de Comercio (República de Colombia, 1971) que le impone tal obligación, sin distinción alguna, incluso debe hacer una oferta de pago parcial si la provisión de fondos no está completa en relación con el importe.

La regulación vigente en Colombia tiene al cheque, como se dijo al principio, con una clara función, la de ser medio de 
pago. El profesor Trujillo concluye: "El mejor cheque es el que se paga inmediatamente en tanto está cumpliendo su función cabalmente, un plazo impuesto al cheque sería una salvedad incompatible con su esencia" (Trujillo, 2003, p. 231).

En un sentido similar, el profesor Narváez (2002), al conceptuar sobre el artículo 714 del Código de Comercio, dice: "La exigencia legal de provisión de fondos tiende a que el cheque no sea considerado un instrumento de crédito sino un medio de pago" (p. 147).

En ese mismo sentido, dos autores refieren: "Se gira un cheque para disponer de una suma de dinero, mientras que por la letra se quiere obtener una suma de dinero; por lo tanto, el cheque es un medio de pago, sirve para cancelar obligaciones en una relación subyacente entre girador y tomador, independientemente de la existencia misma del título" (Peña y Ruiz, 1997, p. 233).

Si bien en la legislación colombiana se consagran unas fechas para la presentación, no quiere decir que se trate de plazos legales para el pago o cumplimiento de la obligación cambiaria, pues, desde que se hace el libramiento del cheque, el beneficiario o tenedor puede hacerlo efectivo en el banco librado.

Dado que el pago es el cumplimiento de la prestación debida, y al cheque desde el proyecto INTAL se le dio esa función, en la realidad doctrinal, jurisprudencial y legislativa colombiana no se ha contemplado la posibilidad de darle una alternativa negocial diferente al del vehículo del pago. "No es jurídicamente posible, en consecuencia, entregar cheques como garantía ni como prenda de una obligación" (Becerra, 2004, p. 295).

Como se afirmó antes, en los negocios entre los comerciantes, la utilidad de los instrumentos jurídicos que le otorga la ley no es limitante para que los ciudadanos, en uso de sus derechos subjetivos, encuentren alternativas para tender puentes que les permitan satisfacer necesidades propias.

La muralla que representa la naturaleza jurídica del cheque y su función económica, hoy por hoy representa un des- 
conocimiento del fin mismo del derecho privado, que es precisamente la satisfacción de necesidades del ciudadano en el campo de su patrimonio, su familia y la institucionalidad. Si el cheque posfechado se utiliza en el mercado, pero la ley desconoce esta realidad, representa una contradicción en los fines del Estado en cuanto a la protección de la propiedad frente a un instrumento formal que podría significar una significativa facilidad en los negocios crediticios.

Llegados a este punto, resulta claro que conocer la causa del derecho es responder la pregunta que interroga por el ser de la persona humana. La respuesta permitirá comprender que la causa de los derechos patrimoniales es un ser biológico único e irrepetible, con necesidades materiales, capaz de satisfacerlas de manera voluntaria, sirviéndose naturalmente de cosas constitutivas del entorno que conoce y somete a su imperio (García, 2001, p. 5).

Ahora bien, desde otro ángulo algunos tratadistas reconocen que el cheque está cumpliendo la función de servir como instrumento de crédito, verbigracia Ravassa (2003) lo expresa en estas palabras:

El cheque es pagadero siempre a la vista. Pero la práctica comercial nos dice que en muchos casos se giran y entregan cheques posdatados. Pues si bien, si esto tuvo relevancia en otras épocas en el campo del derecho penal, ciertamente en el derecho comercial no la tiene (p. 448).

El profesor Galgano (1999) también menciona que el cheque tiene como principal función económica la de ser medio de pago, y considera que su uso como instrumento de crédito es una utilidad indirecta, no obstante, destaca que la jurisprudencia italiana considera al cheque posdatado en procesos de quiebra como una forma normal de pago. (I, II, p. 57; II, p. 107).

Lopera (1999) menciona que el cheque por ser medio de pago, aunque en ocasiones circule, no tiene opción de ser documento de crédito, pero, a su vez, pronostica que por el uso de trasferencias electrónicas su función como medio de pago 
irá perdiendo importancia por el masivo uso de medios electrónicos en las transacciones en una sociedad "cashless".

Contemplar un cheque como instrumento de crédito, o como opción de obtener dinero, no es descabellada, porque esa situación tiene sustento en los usos mercantiles, además de ser una cuestión de disposición de intereses patrimoniales. Asimismo, como se va a mostrar, no solo en Italia se han contemplado usos diversos al de medio de pago para el cheque, sino que también en países de América Latina se han realizado las modificaciones necesarias para darle opciones negociales a los particulares con este instrumento.

Las relaciones de crédito pueden devenir de un cheque, no solo porque es una práctica de común ocurrencia, sino porque su reglamentación contribuye al robustecimiento del derecho comercial. "El derecho mercantil es en esencia una disciplina que depende en su evolución de la configuración y la estructura de la comunidad en la cual se desenvuelven las instituciones que lo integran" (Balmaceda, 2011, p. 53).

\section{B. Cheque de pago diferido}

El caso del cheque de pago diferido se ha venido abriendo paso, desde los usos comerciales, a manera del cheque posfechado, el cual, como se ha dicho, no tiene asiento legal hasta convertirse en una nueva institución cambiaria, plenamente reconocida en países sudamericanos tales como: Argentina, Uruguay, Perú y Paraguay.

En Argentina, desde diciembre de 2003, las empresas pueden cotizar sus cheques de pago diferido en la Bolsa de Comercio de Buenos Aires.

Según la Comisión Nacional de Valores, organismo encargado de controlar el mercado de capitales en la Argentina, en 2006, el monto negociado fue de 431 millones de pesos a una tasa de 11,4\% plazo promedio, según el Ministerio de Economía y Producción. (Comisión Nacional de Valores, con base en datos del Instituto Argentino de Mercado de Capitales, IAMC) 
El jurista argentino Gómez Leo (1997) define al cheque de pago diferido:

Como un título de crédito cambiario, abstracto, formal y completo, que contiene una orden incondicionada de pago a una fecha futura y determinada, librado contra un banco, para que pague al portador legitimado que presente el Cheque de Pago Diferido, una suma determinada de dinero si hubiera suficiente provisión y disponibilidad de fondos en la cuenta contra la cual se giró, y que en caso de ser rechazado, con las debidas constancias, otorga acción cambiaría y ejecutiva contra el librador y, en su caso, contra todos los demás firmantes (Gómez, 1997).

En referencia a la negociación de este título valor en el mercado de capitales argentino, refiere Bavera (2007):

La Comisión Nacional de Valores permite la negociación de los cheques de pago diferido en las Bolsas de Comercio. Esta posibilidad implica un nuevo mercado de crédito (una forma de obtención de liquidez), sobre todo para las PyMEs, que son las que no poseen los canales de financiamiento formales para descontar los cheques que reciben y por ello, muchas veces, recurren al mercado negro donde sufren fuertes quitas (p. 1).

El artículo 54 de la Ley 24.452 (República Argentina, 1995), conocida en Argentina como Ley de Cheques, define al cheque de pago diferido como una orden de pago librada a una fecha determinada posterior a la fecha de su libramiento contra una entidad financiera (art. 54).

La operación que se realiza con estos títulos a fin de obtener efectivo es el descuento, que no es otra cosa que vender los cheques diferidos a fin de obtener dinero en efectivo anticipadamente a la fecha de vencimiento del cheque.

En Argentina, estos títulos-valores son negociados en bancos, bolsas de valores y las llamadas mesas de dinero informal o "cuevas", lo cual de forma alguna debe ser el modelo a seguir en nuestro país, dado que en estos lugares las transacciones no pueden ser detectadas por el Gobierno, a efectos impositivos y ante cualquier incumplimiento la opción de la protección de la jurisdicción queda bloqueada. 
Con la vigencia del cheque de pago diferido no solo empresas sino personas naturales que sean beneficiarios de este título-valor pueden valerse de un comisionista de bolsa para que lo ponga en negociación en el mercado bursátil. La ganancia para los inversionistas es el valor menor que pagan, del mayor que reciben al vencimiento del instrumento, es decir, a la fecha diferida de pago.

La figura del descuento de los cheques de pago diferido aplicado al mercado de valores le otorga a su tenedor la posibilidad de cobrar el instrumento a futuro, en un plazo máximo de 360 días, cobrando interés del plazo, o percibir el dinero anticipadamente por medio de las bolsas de valores, donde quienes tienen efectivo puedan ponerlo a producir, comprando estos cheques a menor precio, ganando en la diferencia pactada y en los intereses generados por el plazo.

En este tipo de cheque, como en cualquier otro, el librador tiene la obligación de tener provisión de fondos o la autorización de girar en descubierto dentro del cupo brindado por el banco, se cree que, en este instrumento, la obligación de provisión es esencial para su éxito financiero, en especial, cuando se trata del mercado de valores en el cual la transparencia es uno de sus principios.

En la Bolsa de Comercio de Buenos Aires, con referencia a los cheques de pago diferido se han reglamentado tres sistemas de negociación, según quién se responsabilice por el pago.

El sistema patrocinado. Este sistema de negociación es propio tanto de grandes empresas como de PYMES, dentro del marco de cooperativas, personas jurídicas de derecho civil como fundaciones y corporaciones mutuales. Requiriéndose la autorización de la Bolsa de Comercio de Buenos Aires, este esquema permite que su negociación se haga en corto tiempo, es decir, se pueden hacer líquidos rápidamente.

La cotización de cheques de pago diferido bajo este sistema se sirve de la Caja de Valores S.A. que obra como depósito centralizado de valores, la cual recibe los instrumentos, así como los endosos que se hagan del instrumento, por medio de la anotación en cuenta. La intermediación está a cargo de so- 
ciedades comisionistas de bolsa, quienes depositan en cuenta corriente los dineros de la venta a favor del beneficiario.

Dada la naturaleza de ser medio de pago de los cheques y sus plazos cortos; y venir de un contrato de cuenta corriente bancaria, donde deben estar los fondos depositados para su pago, lo cual no obedece a un proceso complejo como es la emisión de valores en oferta pública, se cree que es la razón para que no tengan calificación del riesgo, en el sentido de que el objeto de estudio del riesgo será exclusivamente el comportamiento de la cuenta corriente bancaria de la empresa, no sus proyecciones de negocios ni sus aspectos contables, etc.

Llegado el vencimiento del instrumento, el emisor debe tener provisión de fondos en cuenta corriente o autorización para girar en descubierto; el inversionista, desde luego, es el beneficiario del dinero de esta operación.

$\mathrm{Al}$ igual que en los demás títulos valores, la obligación cambiaria está en el girador, los endosantes y sus avalistas, así como lo reglamenta la Ley de Cheques 24.452. La Caja de Valores S.A., a pesar de recibir por endoso en administración el cheque, no es obligado cambiario.

El sistema avalado. Este sistema combina el modelo de cheque de pago diferido con el de la sociedad de garantía recíproca en el sentido de que esta última obra como el puente para que la pyme se beneficie de los fondos de los inversores en el mercado de valores emitiendo cheques de esta clase, los cuales deben tener avalista, que no es otra persona que la sociedad de garantía recíproca donde la pyme emisora es socio.

La Bolsa de Comercio de Buenos Aires determina que el sistema avalado es exclusivo para pymes o personas físicas. Las pymes deben hacerse socios de una sociedad de garantía recíproca que tenga autorización para cotizar cheques en el mercado bursátil argentino. El proceso consiste en que la pyme interesada entrega sus cheques, o los de sus clientes, a una SGR a fin de que éstas realicen su acto de garantía o aval; posterior a ello, se colocan en el mercado de valores para su negociación. Los inversionistas pueden gozar del aval de una tercera entidad que puede, dado el caso, responder por 
los fondos invertidos. El acto de colocación puede ser llevado a cabo por un comisionista de bolsa.

Llegado el vencimiento, como es connatural en estos instrumentos, el beneficiario presenta el cheque al banco para su cobro; el emisor debe tener provisión de fondos o sobregiro que le permita girar en descubierto. Es la forma normal como debe terminar ese negocio jurídico.

Los cheques endosados. En este tercer sistema, las sociedades cotizantes de acciones en la Bolsa pueden negociar los cheques de sus clientes en el mercado, es decir, se realiza una operación de redescuento en el mercado secundario en bolsa de valores.

Como se puede observar, en Argentina, el cheque de pago diferido no solo es una forma evolucionada de este instrumento, sino que se trata de una alternativa de obtener recursos para las pequeñas y medianas empresas, incluso con apoyo de las SGR, que les permite acceder al mercado de valores.

En Perú se encuentra legislación sobre el cheque de pago diferido, concretamente en la Ley N² 27287 (República del Perú, 2000), vigente a partir del 19 de junio de 2000, la cual ha incluido esta suerte de instrumento como un cheque especial, con otros, como el cheque de giro y el cheque garantizado.

El plazo entre el giro o creación al de la fecha de pago o desembolso no debe exceder 30 días, término que en nuestro concepto es bastante corto, perdiéndose la oportunidad de darle al cheque una función más amplia a la de ser medio de pago. En este sentido, Flores (2001), citado por Linares, dice: "Respecto al cheque, la nueva Ley introduce muchas innovaciones para facilitar su manejo, pero lo fundamental (...) es que mantiene la naturaleza jurídica del cheque como instrumento de pago." (s.f., p. 295).

El cheque de pago diferido en el Perú tiene todas las posibilidades de negociación dentro del término de 30 días mencionados, también es posible la limitación en su negociabilidad, que impedirá cualquier transferencia. Si el banco llegara a pagar el cheque diferido antes del plazo a partir del cual es pagadero, deberá responder ante el librador, pues habrá incumplido una condición esencial de los títulos-valores en lo que refiere a 
la cláusula "páguese a partir de" expresamente inserta en el documento. La legislación peruana da la opción a los bancos de expedir formularios de chequera especiales para cheques de pago diferido, no obstante, al no ser obligatorio, es posible en el cheque común insertar la fecha de ser "pagadero a partir", sin sobrepasar los 30 días a partir de la emisión.

En Uruguay se encuentra la norma más antigua sobre cheque de pago diferido. Se trata de la Ley $\mathrm{N}^{\circ} 14.412$ (1975), que en el artículo $3^{\circ}$ contiene la definición del cheque de pago diferido en los siguientes términos:

Es una orden de pago que se libra contra un Banco en el cual el librador, a la fecha de presentación estipulada en el propio documento, debe tener fondos suficientes depositados a su orden en cuenta corriente bancaria o autorización expresa o tácita para girar al descubierto (República Oriental del Uruguay, 1975).

El plazo máximo que otorga la legislación uruguaya es de 180 días (artículo 73 de la citada ley); también se exige que debe estar en el cuerpo del instrumento que se trata de un cheque de pago diferido.

En Uruguay, puede ponerse en evidencia que de las exigencias legales y el plazo de pago del cheque de pago diferido justifican la adopción del instrumento, al contrario de la legislación peruana que ha sido bastante timorata y contradictoria al darle un plazo tan corto y no querer liberarlo de la mera función de medio de pago, lo que precisamente constituye la esencia del cheque especial que se ha estudiado a lo largo de este escrito.

\section{CONCLUSIONES}

1. Dado los usos comerciales y socioeconómicos del cheque y las experiencias del derecho comparado, es totalmente pertinente que desde la doctrina se impulse al legislador a realizar las reformas que conlleven a la implementación del cheque de pago diferido en Colombia, lo que significará la apertura a alternativas negociables, que al tener amparo legal, fortalecerán al derecho comercial como disciplina jurídica. 
2. Permitir la implementación del cheque de pago diferido podría incluso permitir el acceso al crédito a pequeñas y medianas empresas, por tal razón deberán incluirse plazos suficientes para tal fin, siendo necesario adoptar modelos de respaldo financiero, como el de avales de otras sociedades comerciales; teniendo como fuente la experiencia argentina, podría también significar para aquel sector incursionar realmente en el mercado de valores.

3. El cheque de pago diferido es una muestra más de que los usos y costumbres son fuente primigenia del derecho comercial; ahora bien, esta clase de instrumento no es la formalización del cheque posdatado, se trata de la regulación y reglamentación de la postergación del pago, en parámetros literales y claros establecidos en el instrumento que le darán la formalidad y literalidad propia de un título-valor, no solo de un medio de pago.

4. La nueva regulación implicará la existencia de dos tipos de cheque, el común y el de pago diferido, incorporando para este último plazos o términos entre libramiento y vencimiento, sin cometer el error de la legislación peruana, proyectando medianos, y hasta plazos largos, que le permitan una cualidad de instrumento financiero negociable en bolsa de valores.

\section{REFERENCIAS}

Agudelo, M. (2001). Humanismo Jurídico, el Derecho desde una actitud humanista. Bogotá: Leyer.

Balmaceda, M. (2011). El Derecho Comercial Frente a Nuevos Paradigmas. Derecho Comercial en la Era de la Globalización. Bogotá: Ediciones Doctrina y Ley Ltda.

Bavera, P. A. (2007). Otra alternativa de financiación para PyMEs: negociación de cheques de pago diferido en Bolsa. Recuperado de: http://www.baverayasociados.com.ar/wpcontent/uploads/2011/06/Financiamiento-para-PymesCheques.pdf 
Becerra, H. A. (2004). Derecho Comercial de los Títulos Valores. Bogotá: Ediciones Doctrina y Ley Ltda.

Bohórquez, A. (1998). De los Negocios Jurídicos en el Derecho Privado Colombiano. 2 ed. Bogotá: Universidad Autónoma de Bucaramanga.

Flores, P. (2001). Comentarios a la Nueva Ley de Títulos Valores $N^{\circ} 27287.1$ ed. Lima: Jurista Editores. p. 295

Galgano F. (1999). Derecho Comercial. El Empresario. Volumen I y II. Bogotá: Temis S.A.

García, J. A. (2001). Derecho Económico de los Contratos. Bogotá: Ediciones Librería del Profesional.

Gómez, O. R. (1997). El Cheque de Pago Diferido. Buenos Aires, Argentina: Ediciones Depalma.

Linares, J. J. (s.f.). El cheque de pago diferido. Recuperado de: http://www.jusdem.org.pe/articulosinteres/CHEQUE\%20 DE\%20PAGO\%20DIFERIDO\%200K.pdf

Lopera, L. J. (1999). Títulos Valores. Medellín: Señal Editora.

Narváez, J. I. (2002). Derecho Mercantil Colombiano, TítulosValores. Editorial Legis.

Peña, L. y Ruiz, J. (1997). Curso de Títulos Valores. Medellín: Biblioteca Jurídica Dike.

Ravassa, G. J. (2003). Derecho Comercial Bienes Mercantiles. Títulos Valores. Tomo II. Bogotá: Ediciones Jurídicas Gustavo Ibañez.

República de Colombia. Presidencia de la República. (Marzo 27 de 1971). Por el cual se expide el Código de Comercio. [Decreto 410]. DO: 33.339. Bogotá, D. C.: Imprenta Nacional de Colombia.

República Argentina. Senado y Cámara de Diputados de la Nación Argentina. (Febero 22 de 1995). Ley de cheques. [Ley 24.452]. Recuperado de: https://www.santafe.gov.ar/index.

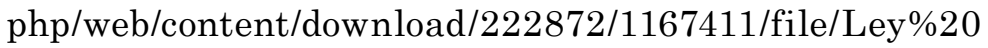
N\%C2\%BA\%2024452-95\%20-\%20Ley\%20de\%20cheques. pdf

República del Perú. Congreso de la República. (Junio 19 de 2000). Ley de títulos valores. [Ley 27.287]. DO: El Peruano. Recuperado de: http://www.leyes.congreso.gob.pe/Documentos/Leyes/27287.pdf 
República Oriental del Uruguay. Consejo de Estado. (Julio 29 de 1975). Cheques. Se fijan nueva normas para su aplicación. [Ley 14.412]. Recuperado de: https://webcache. googleusercontent.com/search?q=cache:A8EdIh0u_5Y J:https://parlamento.gub.uy/documentosyleyes/leyes/ ley $/ 14412+\& c d=2 \& h l=e s-419 \& c t=c \operatorname{lnk} \& g l=c o$

Trujillo, B. (2003). De los Títulos Valores. Parte Especial. Tomo II. Bogotá: Leyer.

Velásquez, C. A. (1998). Instituciones de Derecho Comercial. $2^{\mathrm{a}}$ ed. Medellín: Biblioteca Jurídica Dike. 